\title{
Farelo de arroz integral processado por infravermelho em diferentes períodos de tempo na dieta de frangos de corte
}

\author{
Full fat rice bran processed by infrared in different time periods in broiler diets
}

\author{
Gabriel Colombo Pontalti ${ }^{*}$ Patrícia Diniz Ebling ${ }^{\mathrm{I}}$ Araceli Pacheco Villanueva ${ }^{\mathrm{I}}$ \\ Luciana Gonçalves Teixeira ${ }^{\mathrm{I}}$ Andréa Machado Leal Ribeiro ${ }^{\mathrm{I}}$
}

RESUMO

Trata-se de um estudo de metabolizabilidade em frangos de corte Cobb, para testar os benefícios do processamento térmico por infravermelho no farelo de arroz integral (FAI) em diferentes tempos $(0,6,8$ e 10min). O experimento foi realizado através do método de substituição, em que $20 \%$ de uma dieta referência (DR) a base de milho e farelo de soja foi substituída pelos FAIs processados em diferentes tempos. Usou-se um delineamento experimental completamente casualizado com 5 tratamentos e 10 repetições de uma ave. Entre 21 e 28 dias de idade das aves, foi feita a coleta total de excretas, com 4 dias de adaptação às dietas e 3 de coleta. A dieta com FAI 6min teve melhor aproveitamento em relação às demais e foi a única que não piorou os coeficientes de metabolizabilidade em relação à $\mathrm{DR}$. Na comparação da metabolizabilidade dos ingredientes isolados, não houve diferenças estatísticas. Porém, conforme aumentou o tempo de processamento, diminuiu a solubilidade e a metabolizabilidade da proteína. O processamento térmico por infravermelho não foi capaz de melhorar a metabolizabilidade do FAI para frangos de corte.

Palavras-chave: ingredientes, metabolizabilidade, processamento térmico.

\section{ABSTRACT}

This is a study of metabolizability in broilers Cobb, to test rice bran infrared $(R B)$ thermal processed at different times $(0,6$, 8 and 10min). It was used a reference diet (RD) based on corn and soybean in which $20 \%$ of $R B$ was included. The experiment design was completely randomized, with 5 treatments and 10 replicates. Each replicate was a 21 day old bird. After 4 days of diet adaptation, total excreta was collected, during 3 subsequent days. Diet with RBprocessed at 6 was better used than the others, the only one that did not differ from $R D$. Comparing $R B$ processing times, there were no significant difference between them, regarding digestibility. Processing time was negatively related to protein solubility and protein metabolizability. Infrared heat processing was not able to improve FAI metabolizability for broilers.

Key words: ingredients, metabolizability, thermal processing.

\section{INTRODUÇÃO}

O processamento do arroz para consumo humano gera em torno de $9 \%$ de farelo de arroz integral (FAI) (LORENZETT et al., 2012) que pode ser utilizado na alimentação animal. Entretanto, devido ao elevado teor de gordura polinsaturada, este ingrediente apresenta problemas de rancificação hidrolítica (RAMEZANZADEH et al., 1999a) e oxidativa (RAMEZANZADEH et al., 1999b), comprometendo a qualidade nutricional e a vida útil do produto (PARK et al., 2012).

Processamento térmico sob temperaturas acima de $100^{\circ} \mathrm{C}$ inibem as lipases e lipoxigenases, preveninindo a rancificação hidrolítica (SILVA et al., 2006). Porém, altas temperaturas ou excessivo período de exposição de um ingrediente ao processamento podem ter consequências negativas, como a destruição de aminoácidos essenciais e a formação de compostos antinutricionais (JAEGER et al., 2010).

O processamento por infravermelho apresenta maior uniformidade de aquecimento, resultando em menores perdas qualitativas dos ingredientes. Por não utilizar água, não existe influência de solutos e apresenta menores gastos com energia, tornando o processo mais econômico (KRISHNAMURTHY et al., 2008). No entanto, pouco se sabe a respeito dos efeitos do processamento por infravermelho em ingredientes de dietas para animais e seu efeito na metabolizabilidade. Além disso, o processamento térmico pode melhorar a palatabilidade e a qualidade microbiológica dos alimentos.

IDepartamento de Zootecnia, Universidade Federal do Rio Grande do Sul (UFRGS), Avenida Bento Gonçalves, 7712, 91540-000, Porto Alegre, RS, Brasil. E-mail: gabriel_pontalti@yahoo.com.br. *Autor para correspondência. 
Este trabalho teve por objetivo avaliar as alterações observadas na metabolizabilidade da matéria seca, da proteína bruta, da energia bruta e da energia metabolizável do farelo de arroz integral cru e submetido a diferentes tempos de processamento por infravermelho na dieta de frangos de corte, buscando indicar o tempo ideal de processamento.

\section{MATERIAL E MÉTODOS}

Foram utilizados 50 frangos de corte machos Cobb, com 21 dias de idade. As aves foram alojadas em gaiolas metabólicas individuais de 0,10 $\mathrm{m}^{2}$, distribuídas em sala climatizada. A água e as rações experimentais foram ofertadas à vontade. As aves receberam 24 horas de luz artificial por dia.

O farelo de arroz integral (FAI) de um mesmo lote foi, imediatamente após sua obtenção, processado termicamente por infravermelho sob diferentes tempos de processamento. A variação da temperatura da massa foi mensurada através de um termopar e pode ser observada na figura 1.

Foi formulada uma dieta referência (DR) de acordo com as Tabelas Brasileiras (ROSTAGNO et al., 2011), contendo 19,8\% PB; 3140kcal-kg-1 EM; 0,88\% cálcio; $0,43 \%$ fósforo disponível; $1,13 \%$ Lis dig e $0,83 \%$ de Met + Cis dig. Quatro dietas teste foram desenvolvidas usando o método de substituição (MATTERSON et al., 1965), com substituição de
20\% da dieta referência por farelo de arroz processado termicamente. Os tratamentos foram: (1) FAI cru (DR + FAI sem processamento); (2) FAI 6 - (DR + FAI processado por 6 minutos); (3) FAI 8 - (DR + FAI processado por 8 minutos); (4) FAI 10 - (DR + FAI processado por 10 minutos); (5) referência (DR). Estes tempos foram definidos a partir de um ensaio piloto que buscou o tempo mínimo necessário para a massa alcançar a temperatura de $100^{\circ} \mathrm{C}$ (SILVA et al., 2006), e o tempo máximo permitido para que o forno não sofresse nenhum dano.

O delineamento experimental foi completamente casualizado com cinco tratamentos e dez repetições, sendo que a unidade experimental foi composta por um animal.

O experimento foi realizado com coleta total de excretas, com quatro dias para adaptação e três para as coletas (CÓRTES et al. 2009), sendo as coletas realizadas duas vezes ao dia.

As análises das dietas, excretas e farelos foram realizadas de acordo com a AOAC (1995), para matéria seca (MS), proteína bruta (PB) e energia bruta (EB). Também foram realizadas as análises de solubilidade da proteína em $\mathrm{KOH}$ e índice de acidez, de acordo com a AOAC (1995) e a análise de peróxido (AOAC,1995) e de TBAR/malonAldeído (PIKUL et al.,1989), para medir a peroxidação da gordura do FAI. Foram calculados os coeficientes de metabolizabilidade da matéria seca (CMMS), da proteína bruta (CMPB), da

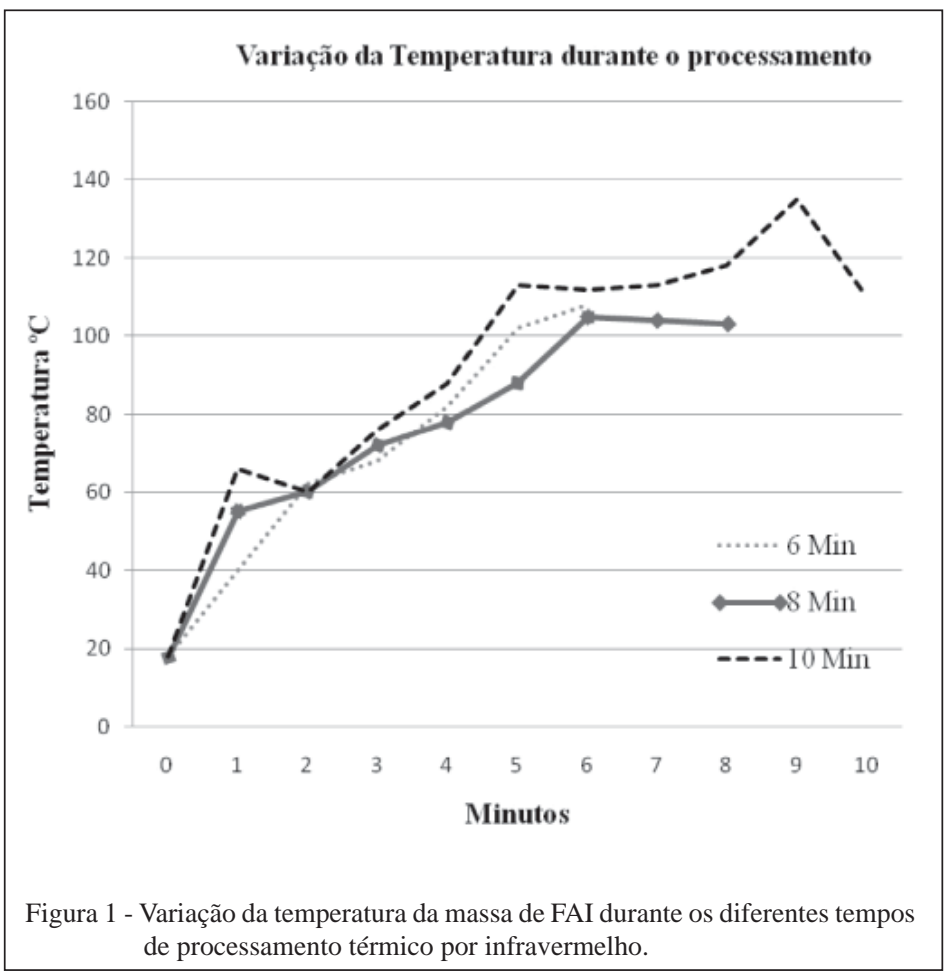

Ciência Rural, v.44, n.3, mar, 2014. 
energia bruta (CMEB), além da energia metabolizável aparente, corrigida para retenção de nitrogênio (EMAn) das dietas segundo os procedimentos padrão descritos em SAKOMURA \& ROSTAGNO (2007). Para o cálculo da EM dos FAI, foi usada a fórmula desenvolvida por CAMPBELL et al. (1983).

Os dados foram submetidos à análise de variância por meio do procedimento GLM (General Linear Model) e as médias comparadas pelo LS Means, usando o software SAS (V. 9.0). Foram testados os modelos de regressão usando contrastes. Quando significativos, as equações de regressão foram geradas.

\section{RESULTADOS E DISCUSSÃO}

Durante o processamento térmico, ocorreu aumento da temperatura da massa de FAI (Figura 1). As temperaturas observadas no processamento por 6 e 8 minutos foram bastante semelhantes, chegando ao máximo de $105 \pm 3^{\circ} \mathrm{C}$. No entanto, no processamento por 10 minutos, a temperatura da massa sofreu um aquecimento mais intenso, principalmente após 8 minutos, com temperatura máxima registrada de $135^{\circ} \mathrm{C}$. Na figura 2, observa-se que o maior tempo de exposição ao calor teve efeito sobre a qualidade da proteína do FAI, com redução na solubilidade da proteína em KOH. Isso pode acontecer, pois maiores temperaturas aumentam as vibrações no interior da molécula proteica, podendo haver o rompimento das interações não-covalentes, favorecendo assim a interação dos grupos hidrofóbicos e fazendo com que a proteína coagule e precipite (PELEGRINE \& GASPARETTO, 2005; PELEGRINE \& GOMES, 2008).

Os resultados de índice de acidez na tabela 1 mostram que todos os farelos tinham baixo índice de acidez em análise feita dois dias após o processo. Após 4 meses de armazenamento, os valores de peróxido foram zero e de TBARS, em mgkg-1, foram 1,46; 1,30 e 1,34 para os FAI 6, 8 e 10min, respectivamente. O FAI cru armazenado também apresentou baixo nível de TBARS (1,11 mgkg-1), mesmo numa situação (sem tratamento térmico) em que as lipases são ativas e levam à produção de ácidos graxos livres e oxidação destes (Ramezanzadeh et al., 1999b). Este fato pode ser explicado porque o malonaldeído, que é a substância quantificada no teste, não é estável por longos períodos de tempo, oxidando-se a álcoois orgânicos e ácidos (OSAWA et al., 2005). LOYPIMAI et al. (2009) observaram que, logo após o processamento por aquecimento ôhmico, os valores de TBARS do FAI ficaram entre 1,2 e $1,4 \mathrm{mgkg}^{-1}$ (inclusive FAI cru) e que o pico de TBARS para o FAI cru foi encontrado 14 dias após a obtenção e chegou a patamares de $3 \mathrm{mgkg}^{-1}$. No entanto, aos 21 dias, este valor já estava ao redor de $2,6 \mathrm{mgkg}^{-1}$.

A adição de FAI cru ou termicamente processado não influenciou no consumo de ração (Tabela 2), resultado este positivo, pois diferentes consumos podem influenciar nos resultados de metabolizabilidade (GIANFELICI et al., 2011). No entanto, a inclusão do FAI diminuiu os coeficientes de metabolizabilidade e a EM das dietas. A dieta com FAI 6 foi a única que não diferiu da referência para nenhuma resposta, enquanto que a dieta com FAI 10 foi pior do que a referência para todos os

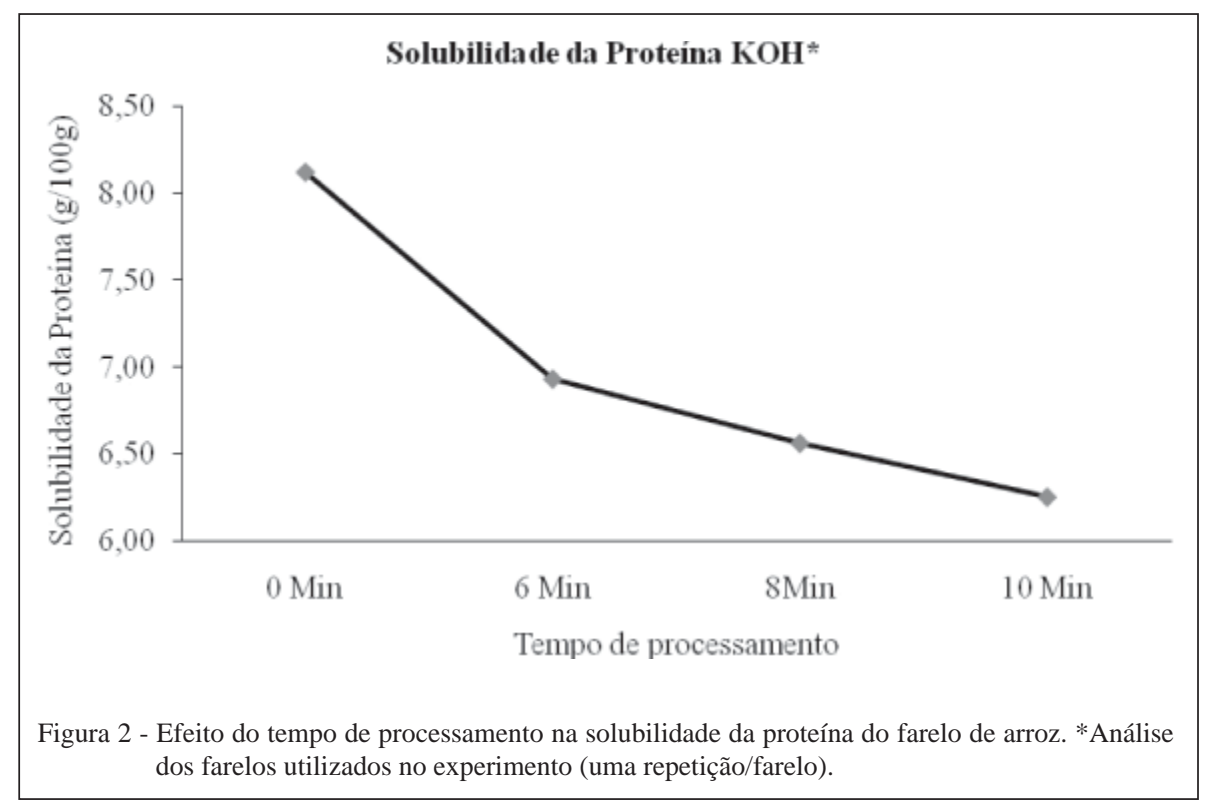

Ciência Rural, v.44, n.3, mar, 2014. 
Tabela 1 - Índice de acidez e coeficientes de metabolizabilidade dos farelos de arroz cru e processados por infravermelho, por 6 , 8 e 10 minutos.

\begin{tabular}{|c|c|c|c|c|c|c|}
\hline \multirow{2}{*}{$\begin{array}{l}\text { Variável } \\
\text { Tratamento }\end{array}$} & \multicolumn{6}{|c|}{-------------------------Farelo de arroz integral-------------------------- } \\
\hline & FAI cru & FAI 6 & FAI 8 & FAI 10 & $\mathrm{P}^{\mathrm{a}}$ & $\mathrm{EPC}^{\mathrm{b}}$ \\
\hline Índice de acidez (mg NaOH g $\left.{ }^{-1}\right)$ & 3,37 & 1,84 & 2,91 & 3,26 & & \\
\hline \multicolumn{7}{|l|}{ Coef. de metabolizabilidade } \\
\hline Matéria seca (\%) & 56,37 & 53,05 & 53,97 & 51,71 & 0,87 & 4,32 \\
\hline Proteína bruta $^{1}(\%)$ & 56,58 & 48,82 & 46,69 & 40,17 & 0,15 & 5,25 \\
\hline Energia bruta (\%) & 64,04 & 66,83 & 64,18 & 63,74 & 0,95 & 4,17 \\
\hline EMAn $\left(\mathrm{kcal} \mathrm{kg}^{-1}\right) \mathrm{MN}$ & 2927 & 3136 & 2959 & 2986 & 0,81 & 173,52 \\
\hline
\end{tabular}

${ }^{\text {a }}$ Significância estatística

${ }^{\mathrm{b}}$ Erro padrão

${ }^{1}$ Regressão linear $(\mathrm{P}<0,05)$.

coeficientes analisados. Esses resultados indicam que o aumento do tempo de processamento exerceu efeitos negativos no aproveitamento do FAI pelos frangos de corte (Tabela 2). Embora apenas as dietas com FAI processados por 8 e 10min tenham diferido estatisticamente da dieta referência com relação ao CMPB, obteve-se uma regressão linear negativa de acordo com a equação $\mathrm{CMPB}=64,62-0,33 *$ minutos de processamento $\left(\mathrm{P}<0,05, \mathrm{R}^{2}=0,10\right)$, mostrando que o aumento do tempo de processamento diminuiu o aproveitamento da PB. Esse resultado está coerente com o gráfico da solubilidade da proteína em $\mathrm{KOH}$. O processamento por 10 minutos pode ter propiciado integração entre açúcares redutores e aminoácidos do FAI. Essas reações podem melhorar características físicas dos alimentos como sabor e coloração, porém podem destruir aminoácidos e produzir substâncias antinutritivas, como os compostos heterocíclicos e as aminas heterocíclicas aromáticas (JAEGER et al., 2010), ajudando a explicar os piores coeficientes observados nesse tratamento.
Observa-se que a dieta com FAI 6 teve maior EMAn, se comparada à do FAI Cru $(\mathrm{P}<0,05)$, sem apresentar diferença com as demais. Esse resultado pode ser explicado pelos resultados de MUJAHID et al. (2003) que, ao avaliarem FAI cru, extrusado e cozido, encontraram pior metabolizabilidade do extrato etéreo para o primeiro.

Embora tenha havido diferenças na comparação entre as dietas, não houve diferenças estatísticas entre os coeficientes de metabolizabilidade dos FAI (ingrediente) (Tabela 1). No método por diferença, os cálculos para os ingredientes teste são indiretos e podem levar a variações muito grandes, como pode ser observado através do erro padrão. Na comparação dos ingredientes, obteve-se uma regressão linear negativa para metabolizabilidade da proteína, de acordo com a equação CMPB=57,15 -0,63*tempo de processamento $\left(\mathrm{R}^{2}=0,16\right)$, mostrando o mesmo fenômeno observado para as dietas experimentais.

Segundo MUJAHID et al. (2004), o tratamento térmico a priori, não melhora a qualidade

Tabela 2 - Consumo de matéria seca e coeficientes de metabolizabilidade de dietas contendo FAI cru e processado por infravermelho ${ }^{(1)}$.

\begin{tabular}{|c|c|c|c|c|c|c|c|}
\hline \multirow{2}{*}{ Variável } & \multicolumn{7}{|c|}{ 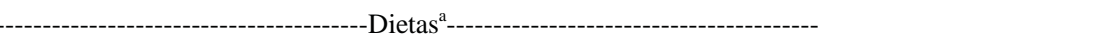 } \\
\hline & DR & FAI Cru & FAI $6^{\text {b }}$ & FAI $8^{c}$ & FAI $10^{\mathrm{d}}$ & & \\
\hline \multicolumn{8}{|l|}{ Tratamento } \\
\hline Consumo matéria seca (g) & 422,7 & 378,7 & 410,8 & 417,9 & 379,2 & 0,54 & 24,11 \\
\hline \multicolumn{8}{|l|}{ Coef. de metabolizabilidade } \\
\hline Matéria seca (\%) & $72,22^{\mathrm{a}}$ & $68,52^{\mathrm{b}}$ & $70,14^{\mathrm{ab}}$ & $68,57^{\mathrm{b}}$ & $68,12^{\mathrm{b}}$ & $<0,05$ & 1,28 \\
\hline Proteína bruta ${ }^{4}(\%)$ & $67,01^{\mathrm{a}}$ & $63,91^{\mathrm{ab}}$ & $64,38^{\mathrm{ab}}$ & $61,94^{\mathrm{bc}}$ & $60,11^{\mathrm{c}}$ & $<0,07$ & 1,24 \\
\hline Energia bruta (\%) & $78,70^{\mathrm{a}}$ & $75,77^{\mathrm{b}}$ & $77,10^{\mathrm{ab}}$ & $75,80^{\mathrm{b}}$ & $75,71^{\mathrm{b}}$ & $<0,08$ & 0,91 \\
\hline EMAn (kcal kg-1) & $3229^{\mathrm{a}}$ & $3075^{c}$ & $3170^{\mathrm{ab}}$ & $3106^{\text {bc }}$ & $3134^{\mathrm{bc}}$ & $<0,07$ & 34,65 \\
\hline
\end{tabular}

${ }^{1}$ Médias seguidas por letras iguais, na linha, não diferem entre si pelo LS-Means, ${ }^{2}$ Significância estatística, ${ }^{3}$ Erro padrão, ${ }^{4}$ Regressão Linear $(\mathrm{P}<0,05)$.

${ }^{\text {a }}$ Exceto para DR, as demais dietas foram compostas por $20 \%$ de FAI.

b processado por 6 minutos, ${ }^{\mathrm{c}}$ processado por 8 minutos, ${ }^{\mathrm{d}}$ processado por 10 minutos. 
do FAI, porém diminui a velocidade de deterioração da qualidade nutricional durante o armazenamento. Estes mesmos autores concluíram que o FAI termicamente processado e armazenado por quatro meses pôde ser usado em até $20 \%$ em rações para frangos de corte. No presente experimento, os farelos foram ofertados às aves logo após a sua obtenção, sendo que, assim, o FAI cru não sofreu oxidação. A comparação com um farelo cru armazenado poderia ter evidenciado os efeitos positivos do processamento térmico. A menor produção de amido resistente também seria outra possibilidade de benefício do tratamento por infravermelho (ZARAGOZA et al., 2010). Neste caso, este tratamento seria vantajoso, quando comparado com outro tipo de processamento, o que poderá ser verificado em futuros trabalhos.

Nas condições experimentais testadas, o tratamento térmico por infravermelho não resultou em incremento do valor nutricional do FAI para frangos de corte. Na literatura, encontramse resultados contraditórios a esse respeito. Por um lado, MUJAHID et al. (2004) observaram aumento no ganho de peso e melhora na conversão alimentar de aves alimentadas com farelo processado termicamente. Por outro, GONZÁLEZ-ALVARADO et al. (2007) não observaram melhor desempenho das aves com grão de milho ou de arroz submetidos ao cozimento

\section{CONCLUSÃO}

O processamento térmico por infravermelho, nos períodos de tempo e temperatura utilizados, não foi capaz de melhorar a metabolizabilidade do farelo de arroz para frangos de corte. Período de aquecimento superiores a 6 minutos, diminuem a digestibilidade da proteína do farelo de arroz.

\section{AGRADECIMENTOS}

Os autores agradecem à Coordenação de Aperfeiçoamento de Pessoal de Nível Superior (CAPES) pela bolsa concedida, à empresa $\mathrm{Hi}$ Tech, em particular a Heidy Christine Jost, por permitir o processamento do farelo de arroz, e ao Programa de Pós Graduação em Zootecnia da Universidade Federal do Rio Grande do Sul, pela oportunidade de estudo e aprimoramento pessoal.

\section{COMITÊ DE ÉTICA E BIOSSEGURANÇA}

Os procedimentos experimentais foram aprovados pela Comissão de ética no uso de animais (CEUA) da Universidade Federal do Rio Grande do Sul sob o protocolo 끌ㄹ․

\section{REFERÊNCIAS}

AOAC (ASSOCIATION OF OFFICIAL ANALYTICAL CHEMISTS). Official Methods of Analysis. Washington: Association of Official Analytical Chemists, 1995. p. 1141.

CAMPBELL, G.L. et al. Calculation of metabolizable energy for ingredients incorporated at low levels into a reference diet. Poultry Science, v.62 p.705-707, 1983. Disponível em: <http:// ps.fass.org/content/62/4/705.abstract> Acesso em 03 jun 2013 doi 10.3382/ps.0620705.

CÓRTES, M.E.M. et al. Study of methodological variations in apparente nutrient metabolism determination in broiler chickens. Revista Brasileira de Zootecnia, v.38 p.1921-1927, 2009. Disponível em: <http://www.scielo.br/scielo.php?pid=S151635982009001000010\&script=sci_arttext $>$ Acesso em 03 jun 2013 doi 10.1590/S1516-35982009001000010.

GIANFELICI, M.F.et al. Determination of apparent metabolizable energy of crude glycerin in broilers chickens. Brazilian Journal of Poultry Science, v.13 n.4 p.255-258, 2011. Disponível em: <http://www.scielo.br/scielo.php?pid=S1516635X2011000400006\&script=sci_arttext $>$ Acesso em 03 jun 2013 doi. 10.1590/s1516-635x2011000400006.

GONZÁLEZ-ALVARADO, J.M. et al. Effect of type of cereal, heat processing of the cereal, and inclusión of fiber in the diet on productive performance and digestive traits of broilers. Poultry Science, v.86 p.1705-1715, 2007.

JAEGER, H. et al. The maillard reaction and its control during food processing. The potencial of emerging technologies. Pathologie Biologie, v.58 p.207-213, 2010. Disponível em <http://www. sciencedirect.com/science/article/pii/S0369811409001941> Acesso em 04 jun 2013 doi 10.1016/j.patbio.2009.09.016.

KRISHNAMURTHY, K. et al. Infrared heating in food processing: an overview. Comprehensive Reviews in Food Science and Food Safety, v.7, p.2-13, 2008. Disponível em <http://onlinelibrary.wiley. com/doi/10.1111/j.1541-4337.2007.00024.x/abstract> Acesso em: 04 jun 2013 doi 10.1111/j.1541-4337.2007.00024.x.

LORENZETT, D.B. et al. Gestão de resíduos na indústria de beneficiamento de arroz. Revista Gestão Industrial, v.8 p.219-232, 2012. Disponível em: <http://revistas.utfpr.edu.br/pg/index.php/ revistagi/article/view/838>. Acesso em: 04 jun. 2013.

LOYPIMAI, P. et al. Effects of ohmic heating on lipase activity, bioactive compounds and antioxidant activity of rice bran. Australian Journal of Basic and Applied Sciences, v.3 p.36423652, 2009

MATTERSON, L.D. et al. The metabolizable energy of feed ingredients of chickens. Connecticut US: The University of. Connecticut, 1965. 119p.

MUJAHID, A. et al. Effect of various processing techniques and storage on nutritional value of rice bran for broiler chicks. Journal of Poultry Science, v.41, p.38-49, 2004.

MUJAHID, A. et al. Nutrient digestibility of broiler feeds containing different levels of variously processed rice bran stored for different periods. Poultry Science, v.82 p.1438-1443, 2003. Disponível em: <http://ps.fass.org/content/82/9/1438.long> Acesso em: 04 jun 2013 
OSAWA, C. et al. Teste de TBA aplicado a carnes e derivados: métodos tradicionais, modificados e alternativos. Química Nova, v.28, p.655-663, 2005. Disponível em: <http://www.scielo.br/ scielo.php?pid=s0100-40422005000400019\&script=sci_arttext> Acesso em 04 jun 2013 doi 10.1590/S0100-4042200500040019.

PARK, C.E. et al. Changes in physicochemical characteristics of rice during storage at different temperatures. Journal of Stored Products Research, v.48, p.25-29, 2012. Disponível em: <http:// www.sciencedirect.com/science/article/pii/S0022474X11000816> Acesso em 04 jun 2013 doi 10.1016/j.jspr.2011.08.005.

PELEGRINE, D.H.G.; GASPARETTO, C.A. Whey protein solubility as function of temperature and $\mathrm{pH}$. Food Science and Technology, v.38 p.77-80, 2005. Disponível em <http://www. sciencedirect.com/science/article/pii/S0023643804001112> Acesso em 04 jun 2013 doi 10.1016/j.lwt.2004.03.013.

PELEGRINE, D.H.G.; GOMES, M.T.de M.S. Whey proteins solubility curves at several temperatures value. Ciência e Natura, v.30 p.17-25, 2008

PIKUL, J. et al. Evaluation of three modified TBA methods for measuring lipid oxidation in chicken meat. Journal of Agricultural and Food Chemistry, v.37, p.1309-1313, 1989. Disponível em <http://pubs.acs.org/doi/abs/10.1021/jf00089a022> Acesso em 04 jun 2013 doi 10.1021/jf00089a022.
RAMEZANZADEH, F.M. et al. Prevention of hydrolytic rancidity in rice bran during storage. Journal of Agricultural and Food Chemistry, v.47, p.3050-3052, 1999a. Disponível em <http:// www.ncbi.nlm.nih.gov/pubmed/10552606> Acesso em 04 jun 2013 doi 10.1021/jf981335r.

RAMEZANZADEH, F.M. et al. Prevention of oxidative rancidity in rice bran during storage. Journal of Agricultural and Food Chemistry, v.47, p.2997-3000, 1999b. Disponível em <http://pubs.acs. org/doi/abs/10.1021/jf981168v> Acesso em 04 jun 2013 doi. 10.1021/ jf981168v.

ROSTAGNO, H.S. et al. Tabelas Brasileiras para aves e suínos. Viçosa: Universidade Federal de Viçosa, 2011. 252p.

SAKOMURA, N.K.; ROSTAGNO, H.S. Métodos de pesquisa em nutrição de monogástricos. Jaboticabal: FUNEP, 2007. 283p.

SILVA, M.A. etal. Preventionofhydrolyticrancidityinricebran. Journal of Food Engineering, v.75, p.487-491, 2006. Disponível em <http:// www.sciencedirect.com/science/article/pii/S0260877405002931> Acesso em 04 jun 2013 doi 10.1016/j.jfoodeng.2005.03.066.

ZARAGOZA, E.F. et al. Resistant starch as functional ingredient: a review. Food Research International, v.43, p.931-942, 2010. Disponível em: <http://www.sciencedirect.com/science/article/ pii/S0963996910000621> Acesso em 04 jun 2013 doi. 10.1016/j. foodres.2010.02.004. 